Indexed by

\title{
SPEED CHANGE AND TRAFFIC SAFETY POWER MODEL FOR INTER-URBAN ROADS WITH HETEROGENEOUS TRAFFIC
}

\section{Martha Leni Siregar}

Universitas Indonesia, Faculty of Engineering, Department of Civil and Environmental Engineering, Kota Depok, Indonesia

\section{Tri Tjahjono}

Universitas Indonesia, Faculty of Engineering, Department of Civil and Environmental Engineering, Kota Depok, Indonesia

\section{Nahry}

Universitas Indonesia, Faculty of Engineering, Department of Civil and Environmental Engineering, Kota Depok, Indonesia

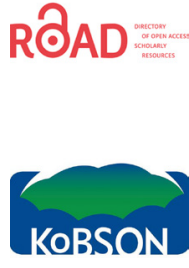

(81) Google

Key words: speed change, power model, heterogeneous traffic, speed ratio, Nilsson's power model, inter-urban, accident modification factor doi: 10.5937/jaes0-29180

Cite article:

Siregar, M. L., Tjahjono, T., Nahry. (2021) SPEED CHANGE AND TRAFFIC SAFETY POWER MODEL FOR INTER-URBAN ROADS WITH HETEROGENEOUS TRAFFIC, Journal of Applied Engineering Science, 19(3) 854-862, DOI:10.5937/jaes0-29180

Online aceess of full paper is available at: www.engineeringscience.rs/browse-issues 


\title{
SPEED CHANGE AND TRAFFIC SAFETY POWER MODEL FOR INTER-URBAN ROADS WITH HETEROGENEOUS TRAFFIC
}

\author{
Martha Leni Siregar, Tri Tjahjono*, Nahry \\ Universitas Indonesia, Faculty of Engineering, Department of Civil and Environmental Engineering, Kota \\ Depok, Indonesia
}

The aim of this study is to develop the power model of the relationship between speed and traffic safety. As the inter-urban roads are characterised with heterogeneous traffic, the heterogeneity became the focus of the analysis. The present study analysed the effects of various types of vehicles through a number of speed change combinations and developed six equations: number of fatal accidents, number of fatalities, number of fatal and serious injury accidents, number of fatal or serious injuries, number of injury accidents and number of injured road users. The results indicated that the Power Model showed high predictability of the speed-accident relationship. The models fit the data well with Rsq in the range of 0.6-0.8. The vehicle category-specific ratio power models exhibited how traffic heterogeneity accounts for traffic safety. The equations' power varies with the types of vehicles, indicating the different sensitivity of accidents and casualties to the speed ratios. Overall, with the power estimates around one, except for all injured victims, the estimates were systematically smaller than those that were initially inferred in Nilsson's Power model. The values indicated that the increase in speed determined the increase in the number of accidents and casualties from year to year. The present study successfully developed the first speed-traffic safety Power Model for Indonesia. As it is exclusively dependent on the speed changes, the model can well describe the direction of change in traffic safety irrespective of other changes in the driving environment factors.

Key words: speed change, power model, heterogeneous traffic, speed ratio, Nilsson's power model, inter-urban, accident modification factor

\section{INTRODUCTION}

Speed has been regarded as the primary indicator of safety. In a crash, the kinetic energy dissipates through friction and mass deformation. The potential mass deformation increases with kinetic energy which is proportional to the vehicle speed squared. Studies on how speed is related to safety have been an interesting area in the traffic safety field. Various regressions with different predictors have been analysed and tested to produce the most satisfying relationship and to demonstrate the magnitude of speed effects in accident occurrences and accident severity. The study by [1] reviewed a number of studies on accident risks and confirmed the high relationship. It was also found that a big speed difference is related to the high accident number. Gargoum and El-Basyouny [2] stated that average speed was found to affect crash frequency and speed increase is associated with collision increase. Using the kinetic energy analogy, Nilsson [3] produced the relationships between speed change and the number of accidents and casualties. The study was a before-after study with a speed limit change from 90 to $110 \mathrm{~km} /$ hour and vice versa. It was found that the decrease in speed limit resulted in a decrease in the average speed and the number of accidents. Nilsson's power models as quoted in [4] are as follow:

Number of fatal accidents $\quad Y_{1}=\left(\frac{V_{1}}{V_{0}}\right)^{4} Y_{0}$

Number of fatalities $Z_{1}=\left(\frac{V_{1}}{V_{0}}\right)^{4} Y_{0}+\left(\frac{V_{1}}{V_{0}}\right)^{8}\left(Z_{0}-Y_{0}\right)$

Number of fatal and serious accidents $Y_{1}=\left(\frac{V_{1}}{V_{2}}\right)^{3} Y_{0}$

Number of fatal or serious injuries $Z_{1}=\left(\frac{V_{1}}{V_{0}}\right)^{3} Y_{0}+\left(\frac{V_{1}}{V}\right)^{6}\left(Z_{0}-Y_{0}\right)$

Number of injury accidents (all) $Y_{1}=\left(\frac{V_{1}}{V_{0}}\right)^{2} Y_{0}$

Number of injured road users (all) $Z_{1}=\left(\frac{V_{1}}{V_{0}}\right)^{2} Y_{0}+\left(\frac{V_{1}}{V}\right)^{4}\left(Z_{0}-Y_{0}\right)$

Speed is denoted by $\mathrm{V}$, variable $\mathrm{Y}$ refers to the accidents, and $Z$ refers to the casualties. Subscript 0 refers to the values observed before a speed change and subscript 1 refers to the values observed after the change.

Comparing power model with exponential model, Elvik [5] supported the use of exponential function and suggested that the function fit well for injury accidents. In the later study, Elvik et al. [6] updated the estimate of the models of the relationship between speed and road safety and found that the mean speed is strongly related to the number of fatalities and number of injury accidents. It was also concluded that both power model and exponential model showed great precision in describing the relationship. 
The interaction effect of the mean speed and the change in mean speed on the accident risks was studied by Tanishita and Wee [7] who found that the highest probability of accidents is when the speed is reduced from $110 \mathrm{kph}$ to $85 \mathrm{kph}$ and when the mean speed is increased from $65 \mathrm{kph}$ to $90 \mathrm{kph}$. The speed variation was defined as the change in mean speed. However, the speed variations resulting from the speed characteristics of different vehicle categories were not considered. As speed variations in different studies vary in the definitions, the impacts on accidents are not always consistent between studies.

Heterogenous traffic has mainly been investigated in countries where the roads are characterised with motorised and non-motorised mixed traffic [8][9]. The studies indicated the importance of considering traffic heterogeneity effects, as stated in the traffic volume composition and speed differences. Other studies also concluded that the average speed and speed deviations of individual vehicles were determined by the various types of vehicles and the volumes [10].

With regards to traffic composition, there have been no studies that relate traffic safety with the changes in speed based on traffic heterogeneity. Generally, speed is regarded as a singular feature which is treated as one value along the roads. As interurban roads in Indonesia are strongly characterised with mixed traffic [11], the heterogeneity needs to be considered when discussing the speed - traffic safety relationship, and the analysis needs to be based on the vehicle category-based speeds. Research results of a particular study may provide an entry to similar researches on similar objectives. Different approaches, however, may be required to fulfil the specific requirements of the studies, particularly those country-specific features and characteristics. The present study defines traffic heterogeneity as the mixture of various vehicles with different speed characteristics sharing the same lane, excluding the non-motorised vehicles.

The main research problem is how the change in speeds determines traffic safety, and which vehicle speeds can be used as a predictor in the relationship of speed and traffic safety.

The results can replace the accident modification factor, which is a multiplicative factor used in predicting the expected change in number of accidents following the implementation of a specific countermeasure at a specific site. The various speed ratios allow predictions of accident numbers and casualties after a given treatment on the average speed of a certain type of vehicles.

\section{DATA AND METHODOLOGY}

\section{Secondary data}

The secondary data were are the 2013-2016 vehicle category-based speed data of two-way inter-urban roads in the Eastern Indonesia obtained from EINRIP (Eastern Indonesia National Road Improvement Project) Report [12]. The six categories of vehicles were: passenger cars $(P C)$, angkots (A), pickups (PU), buses (B), trucks (T) and motorcycles (MC). The EINRIP survey data are considered to contain the most complete traffic data to date with 10,134 cars, 4,230 angkots, 6,084 pickups. 1,001 buses, 6,866 truck and 13,728 motorcycles speeds recorded along 19 arterial roads in 8 provinces in Eastern Indonesia: South Sulawesi, SE Sulawesi, Central Sulawesi, West Kalimantan, South Kalimantan, NTT, NTB and Bali. Angkots (angkutan kota) are mini-van sized vehicles paratransits supplementing the bigger transportation that stop on-demand at irregular points. Pickups are used for cargos and trucks include all types of trucks. Motorcycles are used primarily for transport both for short and long distances and basically not for leisure or joy riding. Non-motorised vehicles were not considered in the categorisation.

\section{Primary data}

The 2019 primary data were obtained through a field survey on three roads. The data were mainly used for model validation of the equations to be developed. Two kinds of speed surveys were conducted: the floating vehicle speed to obtain the road average speed, and the spot speed surveys using speed guns to get the average speeds of vehicles of different categories. In the floating vehicle survey, the survey vehicle was driven at a steady and safe speed following the general flow of the traffic. In principle, the vehicle should overtake as many times as it is overtaken, if safe to do so. The average speeds were calculated from the data of 3-run measurements for each direction of each road. The advantage of the floating vehicle method is that it provides an average value for the whole section. The speed gun survey used a radar device to measure the spot speeds of a random selection of all vehicle types at a series of sites at intervals of approximately $6 \mathrm{~km}$ along each road in both directions.

\section{Accident data and data verification}

The accident data include the number of accidents by severity and number of road users injured by the level of injury obtained from the National Traffic Police Indonesia Road Safety Management System (IRSMS) [13]. The verification of the accident data was done by the second author of this paper, who was involved in EINRIP Project, through police reports at the local precincts to check unreported cases and back-reporting from hospitals to the police. The accident data show that the vehicles involvements in accidents are dominated by motorcycles $(1,497$ vehicles), followed by trucks (161 vehicles), passenger cars (161 vehicles), angkots (101 vehicles), pickups (82 vehicles) and buses (161 vehicles) (IRSMS AIS). The motorcycles' high involvement is in line with Soehodho who stated that motorcycles contributed to around 2 to 3 casualties per day.[14]. Table 1 presents the statistics of accidents $(\mathrm{Y})$, casualties $(\mathrm{Z})$ and speeds $(\mathrm{V})$. 
Table 1: Summary statistics

\begin{tabular}{|c|c|c|c|c|c|}
\hline Variable & Valid N & Mean & SD & Min & Max \\
\hline$Y_{1}$ (fatal accidents) & 88 & 3.2 & 5.1 & 0 & 26 \\
\hline$Y_{0}$ (fatal accidents) & 66 & 2.7 & 4.6 & 0 & 26 \\
\hline$Y_{1}$ (fatal and serious accidents) & 88 & 5.2 & 7.6 & 0 & 38 \\
\hline$Y_{0}$ (fatal and serious accidents) & 66 & 4.5 & 6.9 & 0 & 35 \\
\hline$Y_{1}$ (all injury accidents) & 88 & 13.7 & 20.6 & 0 & 106 \\
\hline$Y_{0}$ (all injury accidents) & 66 & 10.5 & 16.3 & 0 & 75 \\
\hline$Z_{1}$ (fatalities) & 88 & 5.5 & 8.8 & 0 & 41 \\
\hline$Z_{0}$ (fatalities) & 66 & 4.6 & 8.1 & 0 & 41 \\
\hline$Z_{1}$ (fatal and serious injuries) & 88 & 8.9 & 13.0 & 0 & 63 \\
\hline$Z_{0}$ (fatal and serious injuries) & 66 & 7.6 & 11.9 & 0 & 56 \\
\hline$Z_{1}$ (all injured road users) & 88 & 23.8 & 35.9 & 0 & 185 \\
\hline$Z_{0}$ (all injured road users) & 66 & 18.3 & 28.7 & 0 & 127 \\
\hline $\mathrm{V}[\mathrm{kph}]$ & 88 & 54.4 & 9.2 & 29.4 & 90.2 \\
\hline $\mathrm{Vpc}[\mathrm{kph}]$ & 80 & 62 & 8.6 & 37.1 & 81.5 \\
\hline $\mathrm{Va}[\mathrm{kph}]$ & 79 & 54.7 & 12.1 & 34.4 & 82.0 \\
\hline $\mathrm{Vpu}[\mathrm{kph}]$ & 80 & 56 & 8.8 & 8.1 & 71.8 \\
\hline $\mathrm{Vb}[\mathrm{kph}]$ & 75 & 52.3 & 8.9 & 29 & 82 \\
\hline $\mathrm{Vt}[\mathrm{kph}]$ & 80 & 50.6 & 6.0 & 31.8 & 63.1 \\
\hline $\mathrm{Vmc}[\mathrm{kph}]$ & 80 & 58 & 6.2 & 40.4 & 69.9 \\
\hline
\end{tabular}

\section{Method}

As the objective of the study is to predict the number of accidents and casualties using the speed change, the method with speed ratio as the key moderator is used. With reference to [7] which suggested that both power and exponential models were found to work well in predicting the relationships, the study adopts the power model with the general equation:

$f(x)=\beta x^{m}$

When the independent variable is the speed ratio before and after a time reference, the relationship is described as:

$$
\frac{\text { accident after }}{\text { accident before }}=\left(\frac{\text { speed after }}{\text { speed before }}\right)^{\text {exponent }}
$$

The present study adopts the overall average speeds and the average speeds of categorised vehicles in the relationship with accidents. To capture the effects of traffic heterogeneity, six different speeds of different vehicle categories and the overall average speed were entered into the equations as speed ratios. Panel data on 19 roads from 2013-2016 and 2019 were used. As modelling involves two consecutive periods, 2013 data which contain complete data of all speed categories were used to infer parameters with index 0 . The total number of valid observations was 59 for most of the regressions and a little fewer in cases when a particular variable had missing values.

Using Nilsson's power model as a reference, the model was first applied to check the compatibility with the Indo- nesian accident data based on the significance of the exponent estimates and the predictability in terms of Rsq. Speed was denoted by $V$, accidents by $Y$ and accident victims by $Z$. Subscript $t$ corresponded to period $t$, while $\mathrm{t}-$ to the previous year. There were 59 valid observations with both $\mathrm{V}_{\mathrm{t}}, \mathrm{Y}_{\mathrm{t}}$ and $\mathrm{Z}_{\mathrm{t}}$, as well as $\mathrm{Vt}_{-1}, \mathrm{Yt}_{-1}$ and $\mathrm{Zt}_{-1}$ available. Each observation corresponded to period $t$ when a change in mean speed occurred, which was compared to period $t-1$. Index 1 was for period $t$ and index 0 for period $t_{-}$. The notations were aligned with the original notations used by Nilsson [3].

How heterogeneity defines the change in traffic accident is analysed using the $V_{1} / V_{0}$ ratio for six different vehicle categories as the key moderator, with $Y_{0}, Y_{1}$ and $Z_{0}, Z_{1}$ representing the number of accidents and number of casualties. Analysis was carried out for all six relationships as in formulas 1-6 with the help of STATA commands.

\section{RESULTS}

\section{Determination of predictors using Nilsson's power model}

The original Nilsson's regressions were first estimated using the change in the overall speed expressed as $V_{1} I$ $V_{0}$ ratio as the key moderator. There are two $\beta$ constants as the equations for casualties (Z) are expressed in two terms and the results are given in Table 2.

The use of $Y_{0}$ (number of fatal accidents in base year 0 ) proves to be significant in determining all number of accidents $Y_{1}$ (for various types of accidents in the consec- 
Table 2: Parameter estimates using Nilsson's model

\begin{tabular}{|c|c|c|c|c|c|c|}
\hline & $\begin{array}{c}Y_{1} \text { (fatal acci- } \\
\text { dents) }\end{array}$ & $Z_{1}$ (fatalities) & $\begin{array}{c}Y_{1} \text { (fatal and se- } \\
\text { rious accidents) }\end{array}$ & $\begin{array}{c}Z_{1} \text { (fatal and se- } \\
\text { rious injuries) }\end{array}$ & $\begin{array}{c}Y_{1} \text { (all injury } \\
\text { accidents) }\end{array}$ & $\begin{array}{c}Z_{1} \text { (all injured } \\
\text { road users) }\end{array}$ \\
\hline$\beta 1$ constant & $1.353^{* * *}(5.05)$ & $1.416(0.31)$ & $1.038^{* *}(3.20)$ & $1.090(0.20)$ & $1.049^{*}(2.48)$ & $0.942(0.16)$ \\
\hline$\beta 2$ constant & & $0.739(0.11)$ & & $0.647(0.08)$ & & $0.563(0.07)$ \\
\hline$N$ & 59 & 59 & 59 & 59 & 59 & 59 \\
\hline Rsq & 0.700 & 0.715 & 0.653 & 0.672 & 0.772 & 0.747 \\
\hline AIC & 325.8 & 387.9 & 382.7 & 445.8 & 479.2 & 552.8 \\
\hline BIC & 327.9 & 392.0 & 384.7 & 450.0 & 481.3 & 556.9 \\
\hline$t$ statistics in parentheses & \\
\hline
\end{tabular}

utive year)). $Y_{0}$, however, is not a good predictor for all $Z_{1}$ (various types of casualties in the consecutive year). Regressions with $Z_{1}$ as the dependent variable, despite the high Rsq values, suffered from multicollinearity, resulting in the insignificance of all three power estimates.

\section{Model estimation using vehicle category-based speed ratios}

For consistency, the estimations applied the relationship between $Y_{0}$ and $Y_{1}$, and $Z_{0}$ and $Z_{1}$. The proportionality between periods $t$ and $t-1$ was represented as the speed ratio with power transformation. With the heterogeneity approach, the effects of speed change of a certain vehicle category were all estimated.
The next step of the analysis was to include the various speed ratios of different categories of vehicles to demonstrate the speed of which vehicle category of the six dependent variables works best after the power transformation.

\section{Best performing models}

All six power regressions were re-estimated six times using each ratio, and the ranking of the best predictors was obtained based on the corresponding Rsq values $(>0.65)$. Table 4 shows the speed ratios which are significant in the relationship between all $Y_{1}$ and $Y_{0}$, and $Z_{1}$ and $Z_{0}$ at least at the $5 \%$ significance level. Traditional average speed ratios $\left(V_{1} / N_{0}\right)$ are still the best in predict-

Table 4: Parameter estimates of the best performing models where $\beta$ is significantly positive at the $5 \%$ significance level

\begin{tabular}{|c|c|c|c|c|c|}
\hline Dependent Variable & Ratio Used & $\beta$ & t-Statistic & $\mathbf{N}$ & Rsq \\
\hline 1. $Y_{1}$ (all injury accidents) & $\mathrm{V}_{1} / \mathrm{V}_{0}$ & $1.049^{*}$ & 2.48 & 59 & 0.772 \\
\hline 2. $Y_{1}$ (fatal accidents) & $\mathrm{V}_{1} / \mathrm{V}_{0}$ & $1.353^{* * *}$ & 5.05 & 59 & 0.700 \\
\hline 3. $Y_{1}$ (fatal accidents) & $\mathrm{Vpc}_{1} / \mathrm{Vpc}_{0}$ & $3.556^{\star * *}$ & 4.58 & 59 & 0.694 \\
\hline 4. $Y_{1}$ (fatal accidents) & $\mathrm{Vpu}_{1} / \mathrm{Vpu}_{0}$ & $3.798^{* * *}$ & 4.73 & 59 & 0.688 \\
\hline 5. $Y_{1}$ (fatal accidents) & $\mathrm{Va}_{1} / \mathrm{Va}_{0}$ & $2.314^{* *}$ & 3.38 & 56 & 0.660 \\
\hline 6. $Y_{1}$ (fatal accidents) & $\mathrm{Vt}_{1} / \mathrm{Vt}_{0}$ & $3.776^{* *}$ & 3.29 & 59 & 0.656 \\
\hline 7. $Y_{1}$ (fatal and serious accidents) & $\mathrm{V}_{1} / \mathrm{V}_{0}$ & $1.038^{* *}$ & 3.2 & 59 & 0.659 \\
\hline 8. $Y_{1}$ (fatal and serious accidents) & $\mathrm{Vpc}_{1} / \mathrm{Npc}_{0}$ & $2.314^{*}$ & 2.43 & 59 & 0.645 \\
\hline 9. $Y_{1}$ (fatal and serious accidents) & $\mathrm{Vpu}_{1} / \mathrm{Vpu}_{0}$ & $2.574^{*}$ & 2.57 & 59 & 0.643 \\
\hline 10. $Y_{1}$ (fatal and serious accidents) & $\mathrm{Va}_{1} / \mathrm{Va}_{0}$ & $1.691^{*}$ & 2.17 & 56 & 0.639 \\
\hline 11. $Z_{1}$ (all injured road users) & $\mathrm{V}_{1} / \mathrm{V}_{0}$ & $0.775+$ & 1.64 & 59 & 0.747 \\
\hline 12. $Z_{1}$ (all injured road users) & $\mathrm{Vt}_{1} / \mathrm{Nt}_{0}$ & $2.962^{*}$ & 2.22 & 59 & 0.753 \\
\hline 13. $Z_{1}$ (fatalities) & $\mathrm{V}_{1} \mathrm{~N}_{0}$ & $1.116^{* * *}$ & 4.3 & 59 & 0.714 \\
\hline 14. $Z_{1}$ (fatalities) & $\mathrm{Vpc}_{1} / \mathrm{Vpc}_{0}$ & $2.963^{* * *}$ & 4.04 & 59 & 0.712 \\
\hline 15. $Z_{1}$ (fatalities) & $\mathrm{Vpu}_{1} / \mathrm{Vpu}_{0}$ & $2.992^{\star * \star}$ & 3.85 & 59 & 0.703 \\
\hline 16. $Z_{1}$ (fatalities) & $\mathrm{Vt}_{1} / \mathrm{Nt}_{0}$ & $3.377^{* *}$ & 3.3 & 59 & 0.692 \\
\hline 17. $Z_{1}$ (fatalities) & $\mathrm{Va}_{1} / \mathrm{Va}_{0}$ & $1.816^{* *}$ & 2.78 & 56 & 0.683 \\
\hline 18. $Z_{1}$ (fatal and serious injuries) & $\mathrm{V}_{1} / \mathrm{V}_{0}$ & $0.895^{* *}$ & 2.86 & 59 & 0.672 \\
\hline 19. $Z_{1}$ (fatal and serious injuries) & $\mathrm{Vpc}_{1} / \mathrm{Vpc}_{0}$ & $2.030^{*}$ & 2.25 & 59 & 0.663 \\
\hline $20 . Z_{1}$ (fatal and serious injuries) & $\mathrm{Vpu}_{1} / \mathrm{Npu}_{0}$ & $2.172^{*}$ & 2.29 & 59 & 0.661 \\
\hline$p<0.05,{ }^{* *} p<0.01,{ }^{* * *} p<0.001$ & & & & & \\
\hline
\end{tabular}




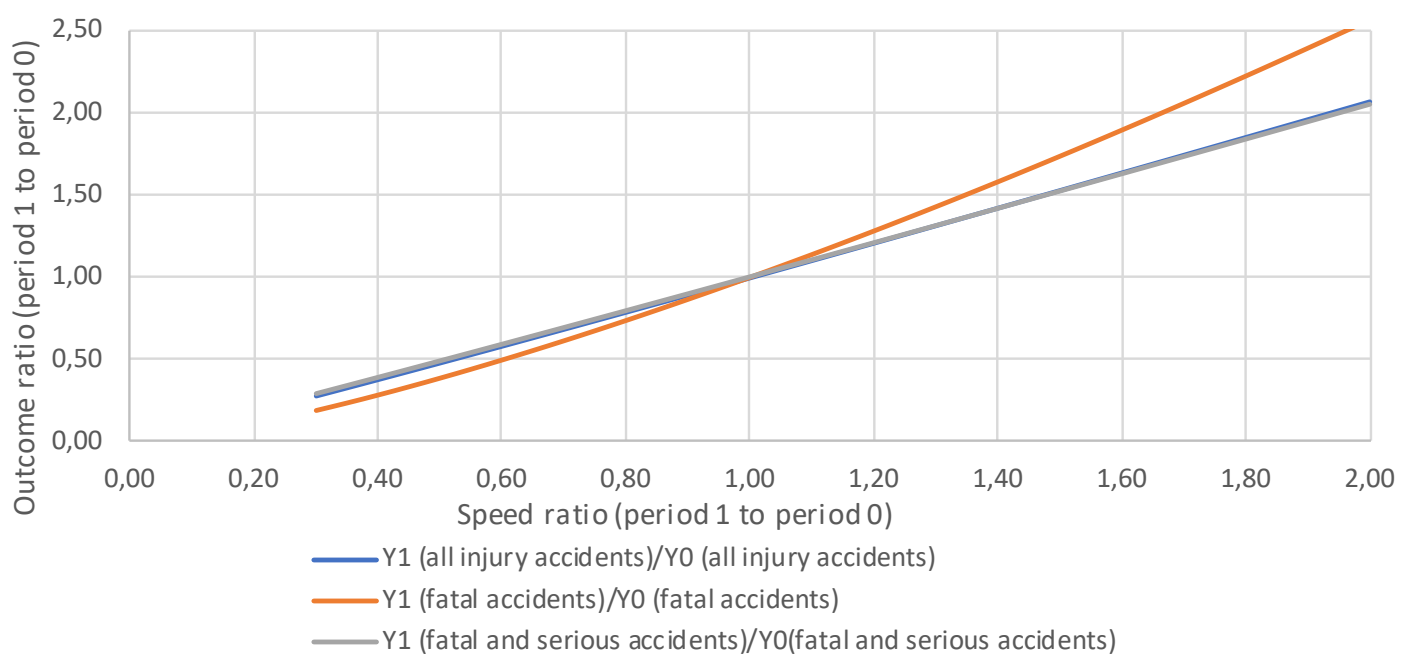

Figure 1: Outcome ratios by severity for different $V_{1} / V_{0}$ speed ratios

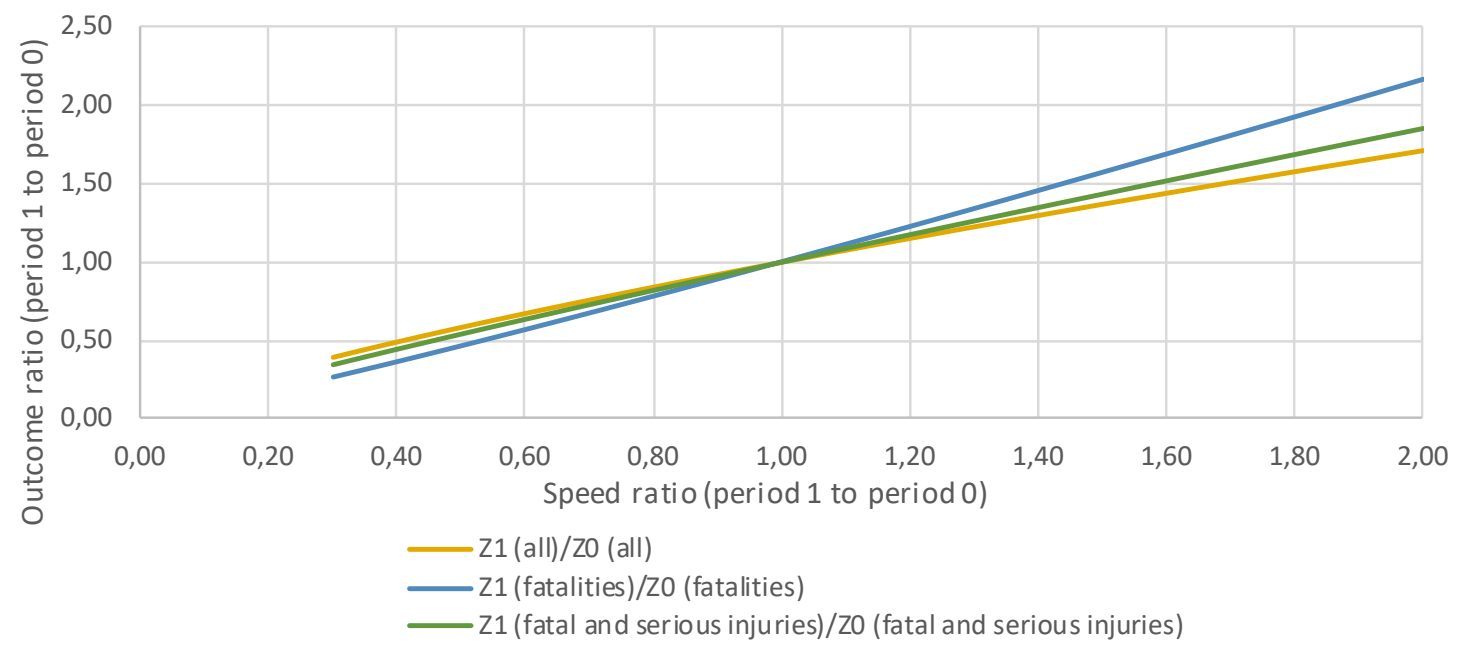

Figure 2: Outcome ratios by casualties for different $V_{1} N_{0}$ speed ratios

ing changes in the number of fatal and fatal and serious accidents and fatalities, as well as the overall number of accidents. Only in the case of the total number of victims the traditional speed ratio appeared to be nonsignificant, and the truck speed ratio $\mathrm{Vt}_{1} / \mathrm{Vt}_{0}$ turned out to be the only significant ratio. Generally, passenger cars, pickups, and trucks specific speed ratios provided a similarly high level of fit. Overall, all power coefficients $\beta$ presented in the table are statistically significant at the $5 \%$ or at a lower significance level.

The accident and casualties' counts are the most predictable with Rsq close to 0.8 . The combined number of fatal and serious cases is the least predictable, but Rsq is still statistically high (Rsq $>0.65$ for the best models). Table 4 also shows that the use of different vehicle-type ratios results in close Rsq values.

The ratio of fatal accidents is systematically higher than the speed ratio when speed increases $\left(V_{1} / V_{0}>1\right)$. The ratios of the total number of accidents and serious and fatal accidents are almost identical to each other and to the speed ratio (power coefficients are very close to 1 ) as can be seen in Figure 1.
As shown in Figure 2 the number of fatal victims grows a little faster compared to speed. For example, when speed goes up by $50 \%\left(V_{1} / V_{0}=1.5\right)$, the number of fatal victims increases by $57 \%$. The total number of victims and the combined number of fatal and seriously injured victims grows a little slower than the speed. However, it should be pointed out that there is a reasonably high homogeneity level in all six estimated power coefficients, which is also confirmed by the fact that none of them is significantly different from 1 at the $5 \%$ level of significance. It is generally hypothesised that minor or non-serious injuries mainly dominate the count of total accidents. The on-site settlement and non-reported accidents might be responsible for the identical graphs of $\mathrm{Y} 1$ (all injury accidents) and $\mathrm{Y} 1$ (fatal and serious accidents).

\section{Practical use of the equations}

The results are applicable in predicting the effects of speed regulations for safety improvement when no other measures are taken. The relative changes in the number of accidents and victims can be approximated directly by the relative changes in the average speed of a cer- 
tain vehicle category. The outcome ratio as in Figures 1 and 2 are basically the multiplicative factor that reflects the expected changes in accident severity and casualties. The outcome ratios of the best performing models can be used as the accident modification factors (AMF) based on the vehicle categories.

\section{Validation of model using 2019 out-of-sample data}

Validation was done using out of sample data from 2019 on 3 roads in South Sulawesi: Jeneponto-Bantaeng, Bantaeng-Bulukumba, and Bulukumba-Tondong. Each of the best performing models and all models were validated using the standard average speed ratio $\left(\mathrm{V}_{1} / \mathrm{V}_{0}\right)$ if they were not among the best according to Table 4 . The general formula used for prediction is as follows:

Dependent variable $_{2019}($ predicted $)=$ Dependent variable ${ }_{2016} \cdot$ Ratio's value $^{\beta}$

As expected, the number of accidents and the number of victims in period $t$ are proportionate to the number of accidents and the number of victims in period $t-1$. The proportionality factor is represented as the ratio of average speed between the two periods of degree $\beta$. Comparison between the predictions using $V_{1} / V_{0}$ ratios of the average traffic speed and the $\mathrm{V}_{1} / \mathrm{V}_{0}$ ratios of all models with the significant power parameter is given in Table 5 . Both predictions show acceptable results of validations, indicating that the models using $\mathrm{V}_{1} / \mathrm{V}_{0}$ ratios provide adequate out-of-sample mean absolute percentage error.

The generalisation of models is also applied for all vehicle category-specific speed ratios, as shown in Table 6 . The absolute error was computed not only for each model individually but also for ensembles (average predictions) corresponding to each dependent variable. For example, the ensemble for $Y_{1}$ (all injury accidents) consisted of just a single model, while the ensemble for $Y_{1}$ (fatal accidents) of 5 models, the ensemble of $Y_{1}$ (fatal and serious accidents) of 4 models, etc. according to the number of rows corresponding to a given dependent variable. Predictions of models comprising each ensemble were averaged out to check if creating ensemble can help improve the base model with the traditional $\mathrm{V}_{1} / \mathrm{V}_{0}$ ratio, which is the speed ratio of the average traffic speed. The total number of predictions was 18 (6 dependent variables* 3 roads. All 3 cases were related to a single road only. It is essential that the model systematically predicted the direction of change in the number of accidents/injuries correctly solely based on speed ratios.

\section{DISCUSSION}

Traffic heterogeneity in this study is represented by the speeds of different categories of vehicles. The results show that some vehicle speed ratios can be used as the key moderators in predicting the change in accidents and casualties. When estimated based on vehicle types, the difference in exponents reflects how the heterogeneity of the historical traffic speeds account for traffic safety. Increasing the average speed of trucks from $50 \mathrm{kph}$ to $55 \mathrm{kph}$ leads to 1.433 times the number of accidents, while the same average speed increase of angkots leads to 1.247 times the number of accidents. The number of fatal accidents is most sensitive to the change in the speed of pickups and trucks, and the number of fatalities is most sensitive to the change in trucks' speed. Despite the high involvement in accidents, the change in motorcycle speeds is not significant in predicting accidents and casualties. The involvement of motorcycles in fatal accidents is likely attributed to the motorcycle speed and the driving environment and interactions. This possibility is supported by Tjahjono [15], who concluded that motorcyclists' improper traffic behaviour could contribute to the high number of road accidents. Lack of restraints imposed on school children riding motorcycles, particularly helmet wearing, seems to be one of the major causes of accidents involving motorcyclists.

The power estimates vary a little depending on the dependent variables, but overall, the values are around one and are systematically smaller than those that Nilsson initially inferred. However, even power estimates around 1 indicate that the increase in the number of accidents and victims from year to year still approximately equals the increase in speed. The smaller power estimates indicating relatively small accidents output may be related to the driving environment where posted speed limits were not present in most lengths of the roads. The results ob-

Table 5: Prediction errors of the base and the ensemble models using traffic average speed

\begin{tabular}{|c|c|c|c|c|c|c|}
\hline \multirow[t]{2}{*}{ Dependent variable } & \multicolumn{3}{|c|}{$\begin{array}{l}\text { Prediction error of the model with } \\
\qquad V_{1} / V_{0} \text { ratio }\end{array}$} & \multicolumn{3}{|c|}{ Prediction error of the ensemble of all models } \\
\hline & 1 & 2 & 3 & 1 & 2 & 3 \\
\hline$Y_{1}$ (all injury accidents) & 0.268 & 0.840 & 1.643 & 0.268 & 0.840 & 1.643 \\
\hline$Y_{1}$ (fatal accidents) & 0.496 & 1.091 & 2.255 & 1.317 & 3.995 & 3.997 \\
\hline $\begin{array}{c}Y_{1} \text { (fatal and serious } \\
\text { accidents) }\end{array}$ & 1.094 & 1.160 & 3.523 & 0.032 & 3.684 & 4.836 \\
\hline$Z_{1}$ (all injured road users) & 6.183 & 23.073 & 23.365 & 5.201 & 34.357 & 33.733 \\
\hline$Z_{1}$ (fatalities) & 0.169 & 5.745 & 5.568 & 2.103 & 8.320 & 7.954 \\
\hline $\begin{array}{c}\mathrm{Z}_{1} \text { (fatal and serious } \\
\text { injuries) }\end{array}$ & 2.536 & 6.655 & 5.926 & 0.849 & 10.405 & 7.716 \\
\hline
\end{tabular}


Table 6: Predictions of various models for the validation set of 3 roads (based on 2019 data)

\begin{tabular}{|c|c|c|c|c|c|c|c|c|}
\hline \multirow{2}{*}{ Dependent variable } & \multirow{2}{*}{ Ratio used } & \multirow{2}{*}{$\beta$} & \multicolumn{3}{|c|}{ Dependent variable $_{2019}$} & \multicolumn{3}{|c|}{ Dependent variable $_{2016}$} \\
\hline & & & 1 & 2 & 3 & 1 & 2 & 3 \\
\hline $\mathrm{Y}_{1}$ (all injury accidents) & $V_{1} / V_{0}$ & 1.049 & 22 & 93 & 86 & 25 & 106 & 99 \\
\hline $\mathrm{Y}_{1}$ (fatal accidents) & $\mathrm{V}_{1} / \mathrm{V}_{0}$ & 1.353 & 3 & 16 & 8 & 3 & 20 & 12 \\
\hline $\mathrm{Y}_{1}$ (fatal accidents) & $\mathrm{Vpc}_{1} / \mathrm{Vpc}_{0}$ & 3.556 & 3 & 16 & 8 & 3 & 20 & 12 \\
\hline$Y_{1}$ (fatal accidents) & $\mathrm{Vpu}_{1} / \mathrm{Vpu}_{0}$ & 3.798 & 3 & 16 & 8 & 3 & 20 & 12 \\
\hline$Y_{1}$ (fatal accidents) & $\mathrm{Va}_{1} / \mathrm{Va}_{0}$ & 2.314 & 3 & 16 & 8 & 3 & 20 & 12 \\
\hline $\mathrm{Y}_{1}$ (fatal accidents) & $\mathrm{Vt}_{1} / \mathrm{Nt}_{0}$ & 3.776 & 3 & 16 & 8 & 3 & 20 & 12 \\
\hline$Y_{1}$ (fatal and serious accidents) & $\mathrm{V}_{1} / \mathrm{V}_{0}$ & 1.038 & 5 & 21 & 8 & 7 & 25 & 13 \\
\hline$Y_{1}$ (fatal and serious accidents) & $\mathrm{Vpc}_{1} / \mathrm{Vpc}_{0}$ & 2.314 & 5 & 21 & 8 & 7 & 25 & 13 \\
\hline$Y_{1}$ (fatal and serious accidents) & $\mathrm{Vpu}_{1} / \mathrm{Vpu}_{0}$ & 2.574 & 5 & 21 & 8 & 7 & 25 & 13 \\
\hline$Y_{1}$ (fatal and serious accidents) & $\mathrm{Va}_{1} / \mathrm{Va}_{0}$ & 1.691 & 5 & 21 & 8 & 7 & 25 & 13 \\
\hline $\mathrm{Z}_{1}$ (all injured road users) & $V_{1} / V_{0}$ & 0.775 & 38 & 146 & 132 & 49 & 185 & 170 \\
\hline$Z_{1}$ (all injured road users) & $\mathrm{Vt}_{1} / \mathrm{Vt}_{0}$ & 2.962 & 38 & 146 & 132 & 49 & 185 & 170 \\
\hline $\mathrm{Z}_{1}$ (fatalities) & $\mathrm{V}_{1} / \mathrm{V}_{0}$ & 1.116 & 5 & 25 & 12 & 6 & 35 & 20 \\
\hline$Z_{1}$ (fatalities) & $\mathrm{Vpc}_{1} / \mathrm{Vpc}_{0}$ & 2.963 & 5 & 25 & 12 & 6 & 35 & 20 \\
\hline$Z_{1}$ (fatalities) & $\mathrm{Vpu}_{1} / \mathrm{Vpu}_{0}$ & 2.992 & 5 & 25 & 12 & 6 & 35 & 20 \\
\hline$Z_{1}$ (fatalities) & $\mathrm{Vt}_{1} / \mathrm{Vt}_{0}$ & 3.377 & 5 & 25 & 12 & 6 & 35 & 20 \\
\hline $\mathrm{Z}_{1}$ (fatalities) & $\mathrm{Va}_{1} / \mathrm{Va}_{0}$ & 1.816 & 9 & 33 & 12 & 6 & 35 & 20 \\
\hline$Z_{1}$ (fatal and serious injuries) & $V_{1} / V_{0}$ & 0.895 & 9 & 33 & 13 & 13 & 44 & 21 \\
\hline$Z_{1}$ (fatal and serious injuries) & $\mathrm{Vpc}_{1} / \mathrm{Vpc}_{0}$ & 2.03 & 9 & 33 & 13 & 13 & 44 & 21 \\
\hline $\mathrm{Z}_{1}$ (fatal and serious injuries) & $\mathrm{Vpu}_{1} / \mathrm{Vpu}_{0}$ & 2.172 & 9 & 33 & 13 & 13 & 44 & 21 \\
\hline
\end{tabular}

\begin{tabular}{|c|c|c|c|c|c|c|c|c|c|}
\hline \multirow{2}{*}{ Dependent variable } & \multicolumn{1}{|c|}{ Dependent variable ${ }_{2019}$} & \multicolumn{2}{|c|}{ Dependent variable ${ }_{2016}$} & \multicolumn{3}{|c|}{ Absolute error } \\
\cline { 2 - 11 } & $\mathbf{1}$ & $\mathbf{2}$ & $\mathbf{3}$ & $\mathbf{1}$ & $\mathbf{2}$ & $\mathbf{3}$ & $\mathbf{1}$ & $\mathbf{2}$ & $\mathbf{3}$ \\
\hline $\mathrm{Y}_{1}$ (all injury accidents) & 0.875 & 0.890 & 0.890 & 21.73 & 93.84 & 87.64 & 0.27 & 0.84 & 1.64 \\
\hline $\mathrm{Y}_{1}$ (fatal accidents) & 0.875 & 0.890 & 0.890 & 2.50 & 17.09 & 10.25 & 0.50 & 1.09 & 2.25 \\
\hline $\mathrm{Y}_{1}$ (fatal accidents) & 0.815 & 0.972 & 0.972 & 1.45 & 18.11 & 10.87 & 1.55 & 2.11 & 2.87 \\
\hline $\mathrm{Y}_{1}$ (fatal accidents) & 0.863 & 1.051 & 1.051 & 1.71 & 24.13 & 14.48 & 1.29 & 8.13 & 6.48 \\
\hline $\mathrm{Y}_{1}$ (fatal accidents) & 0.783 & 0.994 & 0.994 & 1.71 & 19.73 & 11.84 & 1.29 & 3.73 & 3.84 \\
\hline $\mathrm{Y}_{1}$ (fatal accidents) & 0.756 & 1.012 & 1.012 & 1.04 & 20.92 & 12.55 & 1.96 & 4.92 & 4.55 \\
\hline$Y_{1}$ (fatal and serious accidents) & 0.875 & 0.890 & 0.890 & 6.09 & 22.16 & 11.52 & 1.09 & 1.16 & 3.52 \\
\hline$Y_{1}$ (fatal and serious accidents) & 0.815 & 0.972 & 0.972 & 4.36 & 23.44 & 12.19 & 0.64 & 2.44 & 4.19 \\
\hline$Y_{1}$ (fatal and serious accidents) & 0.863 & 1.051 & 1.051 & 4.78 & 28.39 & 14.76 & 0.22 & 7.39 & 6.76 \\
\hline$Y_{1}$ (fatal and serious accidents) & 0.783 & 0.994 & 0.994 & 4.63 & 24.75 & 12.87 & 0.37 & 3.75 & 4.87 \\
\hline$Z_{1}$ (all injured road users) & 0.875 & 0.890 & 0.890 & 44.18 & 169.07 & 155.36 & 6.18 & 23.07 & 23.36 \\
\hline$Z_{1}$ (all injured road users) & 0.756 & 1.012 & 1.012 & 21.42 & 191.64 & 176.10 & 16.58 & 25.64 & 24.10 \\
\hline$Z_{1}$ (fatalities) & 0.875 & 0.890 & 0.890 & 5.17 & 30.74 & 17.57 & 0.17 & 5.74 & 5.57 \\
\hline$Z_{1}$ (fatalities) & 0.815 & 0.972 & 0.972 & 3.27 & 32.22 & 18.41 & 1.73 & 7.22 & 6.41 \\
\hline$Z_{1}$ (fatalities) & 0.863 & 1.051 & 1.051 & 3.85 & 40.58 & 23.19 & 1.15 & 15.58 & 11.19 \\
\hline$Z_{1}$ (fatalities) & 0.756 & 1.012 & 1.012 & 2.34 & 36.44 & 20.82 & 2.66 & 11.44 & 8.82 \\
\hline$Z_{1}$ (fatalities) & 0.783 & 0.994 & 0.994 & 3.85 & 34.62 & 19.78 & 5.15 & 1.62 & 7.78 \\
\hline$Z_{1}$ (fatal and serious injuries) & 0.875 & 0.890 & 0.890 & 11.54 & 39.66 & 18.93 & 2.54 & 6.66 & 5.93 \\
\hline$Z_{1}$ (fatal and serious injuries) & 0.815 & 0.972 & 0.972 & 8.58 & 41.57 & 19.84 & 0.42 & 8.57 & 6.84 \\
\hline$Z_{1}$ (fatal and serious injuries) & 0.863 & 1.051 & 1.051 & 9.43 & 48.99 & 23.38 & 0.43 & 15.99 & 10.38 \\
\hline
\end{tabular}


tained are closer to the results of Mountain et al. [16] who also adopted Power model to investigate the relationship between speeds and accidents.

The model's power estimates were found to be in the range of 1.4 to 1.5 for initial speed around $55 \mathrm{kph}$. Other studies resulted in bigger values of the exponents, as in [16] with 6.5 and also [17] with 10.5. A previous study [18] may support the finding as it showed that highways with posted speed limits were not necessarily safer than highways without posted speed limits. The study revealed that the number of accidents dropped when there were no daytime speed limits and that the people drove the speeds that they were comfortable driving. With the lack of speed limit signs and other standard signs, there is a basic question as to whether the speed behaviour was triggered by the drivers' voluntary speed choices or by the drivers' compliance to the enforced speed limit. In such cases, it can be assumed that the drivers similarly compromise the driving condition in their choice of speed. The different estimate values obtained in the present study may be due to the difference in the traffic conditions. Firstly, the present study was conducted on inter-urban arterial roads. Secondly, the speed choice is more voluntarily decided with the absence of posted speed limits

\section{CONCLUSION}

While estimates of Nilsson's equations provide vital benchmarks previously not available for Indonesia, the present study's more significant contribution is the analysis of the power of alternative predictors, including six vehicle category-specific ratios of average speeds. The different effects of traffic heterogeneity is reflected in the different power estimates for number of accidents and casualties. The results give only the speed ratios with best performance in the predictions of the change in certain groups of number of accidents and casualties.

As it is exclusively dependent on the speed changes, the model can well describe the change in traffic safety irrespective of other changes in the driving environment factors. Therefore, the results can be expected to function as the accident modification factor in predicting the effect of a speed-based safety treatment on a specific category of vehicle.

The results are also useful where posted speed limits are lacking, and when the drivers' speed behaviour and speed choice are mainly determined by their knowledge about the expected speed and by their desirable speeds that comply with the driving environment.

\section{IMPLICATION OF THE WORK}

The present study is the first reporting parameters estimates of power model equations linking changes in speed with traffic safety for Indonesia based on traffic heterogeneity. Motorcycles involvement in accidents needs to be further investigated, both as traffic accident victims and as the precursor to the accidents. As the results show the effect of traffic heterogeneity, how speed variation within a category is associated with traffic safety may need to be investigated. The findings also necessitate studies on heterogeneous flow with higher speeds and different road classifications.

\section{ACKNOWLEDGEMENT}

This research was funded by PDUPT research grant from the Department of Research, Technology and Higher Education of the Republic of Indonesia 2019, contract no: NKB-1668/UN2.R3.1/HKP.05.00/2019. The Authors would also like to thank the EINRIP Project Management Unit of the Australian-Indonesia Partnership EINRIP Project for the permission to use the data.

\section{REFERENCES}

1. Aarts, L. and van Schagen, I.(2006). Driving speed and the risk of road crashes: A review. Accident Analysis \& Prevention, vol. 38, no. 2, p. 215-224. DOl: 10.1016/J.AAP.2005.07.004.

2. Gargoum, S. A. and El-Basyouny, K.(2016). Exploring the association between speed and safety: $A$ path analysis approach. Accident Analysis and Prevention, vol. 93. DOI: 10.1016/J.AAP.2016.04.029.

3. Nilsson, G.(2004). Traffic Safety Dimensions and the Power Model to Describe. Bulletin 221. Lund Institue of Technology, Department of Technology and Society, Traffic Engineering, Lund.

4. Elvik, R., Christensen, P. and Amundsen, A.(2004). Speed and road accidents. Report Number 740/2004, Institute of Transport Economics, Norwegian Centre for Transport Research. ISBN: 82-480-0451-1

5. Elvik, R.(2013). A re-parameterisation of the Power Model of the relationship between the speed of traffic and the number of accidents and accident victims. Accident Analysis and Prevention, vol. 50, p. 854860. DOI: 10.1016/J.AAP.2012.07.012.

6. Elvik, R. et al.(2019). Updated estimates of the relationship between speed and road safety at the aggregate and individual levels. Accident Analysis and Prevention, vol. 123, no. November 2018, p. 114122. DOI: 10.1016/J.AAP.2018.11.014.

7. Tanishita, M. and Wee, B. Van.(2017). Impact of vehicle speeds and changes in mean speeds on per vehicle-kilometer traffic accident rates in Japan. IATSSR, p. 0-5. DOI: 10.1016/J.IATSSR.2016.09.003.

8. Wang, X. et al.(2018). Speed, speed variation and crash relationships for urban arterials. Accident Analysis and Prevention, vol. 113, no. November 2016, p. 236-243. DOI: 10.1016/J.AAP.2018.01.032. 
9. Roy, R., Saha, P. and Kumar, A.(2017). Speed Distributional Trends on Two-lane Roads with Mixed Traffic under Heavy Flow. Procedia Engineering, vol. 187, p. 465-470. DOI: 10.1016/J.PROENG.2017.04.401.

10. Quddus, M.(2013). Exploring the Relationship Between Average Speed, Speed Variation, and Accident Rates Using Spatial Statistical Models and GIS. Journal of Transportation Safety and Security, vol. 5, no. 1, p. 27-45. DOI: 10.1080/19439962.2012.705232.

11. Siregar, M. L., Tjahjono, T. and Nahry.(2020). Endogenous Relationship of Accident Occurrence with Speed, Traffic Heterogeneity and Driving Environment on Inter-Urban Roads in Indonesia. Journal of Applied Engineering Science. doi: DOI: 10.5937/ JAES0-25837.

12. Australia-Indonesia Partnership.(2017). EINRIP Monitoring \& Evaluation Programme, Fifth Monitoring Survey, Final Report.

13. IRSMS Login. Available at: https://irsms.korlantas. polri.go.id/login (Accessed: 23 March 2019).

14. Soehodho, S.(2017). Public transportation development and traffic accident prevention in Indonesia. IATSS Research, vol. 40, no. 2, p. 76-80. DOI: HTTPS://DOI.ORG/10.1016/J.IATSSR.2016.05.001.
15. Tjahjono, T.(2016). Identification of motorcycle crashes and possible roadside protection on rural low-volume roads in Indonesia. Transportation Research Circular. Transportation Research Board. Available at: http://www.trb.org/Main/Blurbs/175369. aspx.

16. Mountain, L. J., Hirst, W. M. and Maher, M. J.(2005). Are speed enforcement cameras more effective than other speed management measures? The impact of speed management schemes on $30 \mathrm{mph}$ roads. Accident Analysis \& Prevention, vol. 37, p. 742-754.

17. Kloeden, C., Woolley, J. and McLean, J.(2007). A Follow-up Evaluation of the $50 \mathrm{~km} / \mathrm{h}$ Default Urban Speed Limit in South Australia. in Proceedings of Australasian Road Safety Research, Policing and Education Conference. DOI: HTTPS://DOI. ORG/10.1016/J.AAP.2018.11.014.

18. Islam, M. T. and El-Basyouny, K.(2015). Full Bayesian evaluation of the safety effects of reducing the posted speed limit in urban residential area. Accident Analysis \& Prevention, vol. 80, p. 18-25. DOI: HTTPS://DOI.ORG/10.1016/J.AAP.2015.02.026. 